\title{
MULHERES DO CAMPO, SINDICALISMO E AÇÃO POLÍTICA: A CONSTRUÇÃO HISTÓRICA DA CATEGORIA TRABALHADORA RURAL
}

\author{
Marisangela Lins de Almeida ${ }^{1}$
}

Recebido em: 20/04/2020

Aprovado em: 22/06/2020

\begin{abstract}
Resumo: Neste trabalho analiso a ação política de trabalhadoras rurais que ao longo da década de 1980, protagonizaram um movimento político por reconhecimento do seu trabalho e direitos. Tal análise se desenvolve a partir de cartas de trabalhadoras rurais enviadas à Assembleia Nacional Constituinte e de narrativas orais da Sra. Zenóbia Cedorak de Godoy, sindicalista rural atuante na região central do Paraná. A ideia é mostrar como as categorias Trabalhadora Rural, Gênero e Divisão Sexual do Trabalho se entrelaçam a uma conjuntura de resistência histórica do campesinato brasileiro. Dessa forma, examino a construção coletiva da categoria política Trabalhadora Rural e, mais especificamente, o processo de inclusão e participação (marcado por práticas discriminatórias) das mulheres trabalhadoras rurais no Sindicato Rural de Pitanga, localizado na região Central do Paraná, importante agenciador dos debates sobre direitos previdenciários e participação política das mulheres. Conforme Cordeiro (2006), o uso da nomeação Trabalhadora Rural é bastante recente no Brasil. Desse modo, a partir das memórias da sindicalista e trabalhadora rural Zenóbia Cedorak de Godoy, investigo as nuances das práticas políticas de mulheres do campo que reivindicaram uma única identidade, a de mulheres trabalhadoras rurais, recusando classificações que as identificavam como do lar e, em decorrência, associando-as à esfera doméstica/reprodutiva, assim como negando-lhes direitos. Palavras-chave: Trabalhadoras Rurais; Sindicalismo; Gênero; Trabalho; Categorias.
\end{abstract}

\section{MUJERES CAMPESINAS, SINDICALISMO Y ACCIÓN POLÍTICA: LA CONSTRUCCIÓN HISTÓRICA DE LA CATEGORÍA DE TRABAJADORAS RURALES}

Resumen: En este artículo analizo la acción política de las trabajadoras rurales que, durante la década de 1980, lideraron un movimiento político para el reconocimiento de su trabajo y sus derechos. Este análisis se basa en cartas de trabajadoras rurales enviadas a la Asamblea Nacional Constituyente y narraciones orales de la Sra. Zenóbia Cedorak de Godoy, una sindicalista rural que trabaja en la región central del Paraná. La idea es mostrar cómo las categorías Trabajadora rural, Género y División sexual del trabajo se entrelazan con un contexto de resistencia histórica por parte del campesinado brasileño. Así, examino la construcción colectiva de la categoría política de los trabajadores rurales y, más específicamente, el proceso de inclusión y participación (marcado por prácticas discriminatorias) de las mujeres trabajadoras rurales en la Unión Rural de Pitanga, ubicada en la región central de Paraná, un agente importante de los debates. sobre derechos de seguridad social y participación política de

\footnotetext{
${ }^{1}$ Doutoranda no Programa de Pós-Graduação em História da Universidade Federal de Santa Catarina (UFSC). Email: mary lins_18@hotmail.com. ORCID: https://orcid.org/0000-0001-5110-6022.
} 
las mujeres. Según Cordeiro (2006), el uso del nombre Trabajador rural es bastante reciente en Brasil. Así, desde los recuerdos de la sindicalista y trabajadora rural Zenóbia Cedorak de Godoy, investigo los matices de las prácticas políticas de las mujeres rurales que reivindicaron una identidad única, la de las mujeres trabajadoras rurales, rechazando clasificaciones que las identificaban como hogar y, en en consecuencia, asociándolas a la esfera doméstica / reproductiva, así como negándoles derechos.

Palabras clave: Trabajadoras rurales; Unionismo; Género; Trabajo; Categorías.

\title{
RURAL WORKING WOMEN, SYNDICALISM AND POLITICAL ACTION: THE HISTORICAL CONSTRUCTION OF THE FEMALE RURAL WORKER CATEGORY
}

\begin{abstract}
In this work I analyze letters sent to the National Constituent Assembly and oral narrative of rural working women who, during the 1980s, led a political movement for recognition of their work and rights. The idea is to show how the categories Female Rural Worker, Gender and Sexual Division of Labor intertwine with a context of historical resistance by the Brazilian peasantry Thus, I examine the collective construction of the Female Rural Worker political category and, more particularly, the process of inclusion and participation (marked by discriminatory practices) of rural working women at the Rural Syndicate of Pitanga, in the central region of Paraná, an important agent in the debates on women's social security rights and political participation. According to Cordeiro (2006), the use of the term Female Rural Worker is quite recent in Brazil. So, based on the oral reports of union member and rural worker Zenóbia Cedorak de Godoy, I look into the nuances of the political practices of rural working women who claimed one single identity, that of female rural workers, rejecting classifications that identified them as housewives and, consequently, associating them with the domestic/reproductive sphere as well as denying their rights.
\end{abstract}

Key words: Female Rural Workers; Syndicalism; Gender; Labor; Categories.

Esse texto propõe uma reflexão a respeito da historicidade da categoria trabalhadoras rurais, abordada a partir de sua construção coletiva como categoria política na luta por legitimidade e reconhecimento de direitos. Inicialmente, busco analisar a construção histórica dessa categoria num contexto mais amplo, nacional. Investigo sua emergência social a partir de abordagens teóricas específicas sobre trabalho e participação política das mulheres do campo e, ainda, por meio da análise de cartas enviadas por trabalhadoras rurais à Assembleia Nacional Constituinte (ANC), entre 1986 e 1987.

$\mathrm{Na}$ segunda parte do texto, proponho uma abordagem empírica sobre o processo histórico e político de inserção e atuação das trabalhadoras rurais da Região Central do Paraná no Sindicato de Trabalhadores Rurais de Pitanga, importante veículo na luta pela positivação do trabalho das mulheres rurais ao longo dos anos 1980. 
A partir das memórias ${ }^{2}$ da trabalhadora rural e sindicalista, a Sra. Zenóbia Cedorak de Godoy, problematizo as nuances dessas atuações políticas ao abordar os movimentos sociais rurais fundamentado pelo recorte de gênero $^{3}$. Analisando relações que se processam mutuamente, gênero e classe social, problematizo e historicizo as dificuldades enfrentadas no processo de participação política em busca de reconhecimento e valorização de suas múltiplas atividades no espaço doméstico (casa/quintal) e da roça.

Assim, proponho conduzir essa discussão a partir de teorias sobre a divisão sexual do trabalho. Hirata e Kergoat (2007) historicizam e problematizam o conceito de divisão sexual do trabalho. Segundo as autoras, a divisão sexual do trabalho é a forma de divisão do trabalho social decorrente das relações sociais entre os sexos; para além, é um fator prioritário para a sobrevivência da relação social entre os sexos. Essa forma é modulada histórica e socialmente e tem como características a designação prioritária dos homens à esfera produtiva e das mulheres à esfera reprodutiva e, simultaneamente, a apropriação pelos homens das funções com maior valor social adicionado (políticos, religiosos, militares etc.) ${ }^{4}$.

Para além dessa conceitualização, as autoras apontam dois princípios organizadores: o de separação (trabalhos distintos para homens e mulheres) e o hierárquico (maior valoração ao trabalho masculino). Esses princípios, apesar de legitimados e acatados como naturais não são imutáveis. Concretamente, suas modalidades variam no tempo e no espaço, apresentando grande plasticidade; o que é estável é a distância entre os grupos sexuais.

\footnotetext{
${ }^{2}$ Operamos com a concepção de Portelli (1997, p. 27) de que memórias são interpretações; segundo ele, "aquilo que criamos é um texto dialógico de múltiplas vozes e múltiplas interpretações: as muitas interpretações dos entrevistados, nossas interpretações e as interpretações dos leitores". Ele ressalta ainda que o ato e arte de lembrar são profundamente pessoais, apesar de ser moldada de formas diversas pelo meio social. Nesse sentido, de acordo com os fundamentos teóricos e metodológicos da História Oral, onde autores como Pollak (2010), Antonio Torres Montenegro (2006), Janaina Amado (1995) e Alessandro Portelli (1997) convergem quanto ao entendimento do processo de construção das narrativas, no sentido de que são elaboradas tomando como referência as experiências subjetivas e socialmente compartilhadas.

${ }^{3}$ Sobre a categoria Gênero, a perspectiva fundamenta-se nos debates propostos por Scott (1995), Pedro (2005) e Pinsky (2009), no sentido de reconhecer que a condição feminina e a configuração social dos lugares ocupados por homens e mulheres são construções históricas e sociais, enfatizando os aspectos culturais das diferenças sexuais. Segundo Soihet (2011, p. 266) o termo gênero, desde a década de 1970, tem sido usado para teorizar a questão da diferença sexual. Utilizado inicialmente pelas feministas americanas para ressaltar a ideia de construção social da diferença entre os sexos, a expressão implica numa desnaturalização do determinismo biológico, ligado à ideia do sexo. A categoria gênero traz implícito um sentido de rejeição à oposição binária entre homens e mulheres, desconstruindo a ideia de papéis sociais naturais, colocando o debate no campo das construções sociais e culturais sobre masculinidade e feminilidade.

${ }^{4}$ Hirata e Kergoat (2007) apontam que foi na França, sob o impulso do movimento feminista dos anos 1970, que surgiram os trabalhos que assentariam as bases teóricas do conceito de divisão sexual do trabalho. A problemática da divisão sexual do trabalho é questão central na abordagem de Jany Catrice (2016). Examinando o contexto francês, a autora afirma que, seja no campo ou cidade, a responsabilidade do trabalho doméstico ainda é uma constante na vida das mulheres. Bessin (2016) contribui para a discussão ao tratar sobre as maneiras de abordar à ideia de temporalidades sexuadas da atividade. Para o autor, a experiência temporal das mulheres no trabalho consiste em "uma vida em duas", administrada como uma dupla presença.
} 
Essa distância de valoração do trabalho pode ser pensada também a partir da dinâmica camponesa, onde, historicamente, a categoria trabalho aplica-se somente ao pai de família; no espaço da roça o trabalho das mulheres é definido como ajuda. Considera-se que as mulheres trabalham no âmbito doméstico, mas ainda assim esse trabalho é desvalorizado nesse universo de representações e considerado trabalho leve. Desse modo, mulheres exaustas pela dupla jornada de trabalho exercida dentro de casa e ainda, com as atividades da roça, não alcançavam reconhecimento desse trabalho considerado invisível ou definido como mera "ajuda".

Segundo Paulilo (1987, p. 7): “o trabalho é "leve” (e a remuneração é baixa) não por suas próprias características, mas pela posição que seus realizadores ocupam na hierarquia familiar". Logo, para a autora, o que atribui valor ao trabalho não é a atividade realizada, mas o sexo e a posição de quem executa a tarefa.

$\mathrm{Na}$ construção social dos espaços, o domínio da roça instituiu-se como espaço do masculino, e o espaço da casa, da cozinha e do quintal como fundamentalmente das mulheres, constituindo o espaço do lar como historicamente feminino, mesmo que as mulheres executem atividades ditas masculinas, como a roçada. Assim, dentro e fora, trabalho pesado e trabalho leve tornam-se classificações que associam espaços e atividades às pessoas.

Esmeraldo (2013, p. 240), ao analisar o aspecto simbólico ${ }^{5}$ do trabalho no campo, diz que "a labuta do homem é central para produzir a autoridade masculina [...] Há uma ordem simbólica (moral) que se instala para reger o trabalho camponês e qualificá-lo de forma diferenciada e hierarquizada" ${ }^{\text {. }}$. Dessa forma, problematizar e desconstruir a concepção naturalizada de trabalho e divisão sexual das funções é fundamental para avançarmos na direção de equidade de gênero, seja no campo ou na cidade.

\footnotetext{
${ }^{5}$ Woortmann e Woortmann (1997) auxiliam na compreensão desse fenômeno ao afirmarem que os processos de trabalho possuem dimensões simbólicas que constroem não somente espaços agrícolas, mas espaços sociais e de gênero.

${ }^{6}$ Analisando o caso francês, Hirata e Kergoat (2007), a partir de um recorte de classe, analisam a questão do trabalho doméstico e sua reação com o campo profissional. A ideia de uma complementaridade é analisada a partir de modelos diversos: tradicional (a esfera doméstica é inteiramente responsabilidade das mulheres, homem tem o papel de provedor), conciliação (cabe quase que exclusivamente as mulheres a conciliação da vida familiar e profissional), parceria (presume a ideia de igualdade entre os sexos, não é realidade concreta) e delegação (delegar a outras mulheres as tarefas domésticas e familiares, mesmo as que delegam são responsáveis pela gestão do trabalho delegado). A respeito deste último modelo, as autoras apontam que é necessária uma reflexão crítica que não pode se desenvolver fora das modalidades de reprodução da servidão doméstica e que as razões da permanência da atribuição do trabalho doméstico às mulheres, mesmo no contexto da reconfiguração das relações sociais de sexo, continuam sendo um dos mais importantes problemas na análise das relações sociais de gênero. Segundo as autoras, é necessário refletir sobre como modificar essa situação, questionando os âmbitos psicológicos da dominação e a dimensão da afetividade.
} 


\section{A existência pública da categoria trabalhadora rural}

Nos anos finais da década de 1970 e ao longo de 1980, mulheres rurais mobilizaram-se em diferentes regiões do país, reivindicando, entre outras questões, a valorização do seu trabalho. Conforme Cordeiro (2006), o uso da nomeação trabalhadora rural é bastante recente no Brasil e está diretamente ligado à ação política das mulheres da área rural. Essa ação política, iniciada em escalas regionais, adquire novos contornos, construindo redes de atuação nacional na década de 1980. Mulheres de diferentes realidades e características, reivindicaram uma única identidade, a de mulheres trabalhadoras rurais, recusando classificações que as identificavam como do lar e, em decorrência, associando-as à esfera privada/doméstica/reprodutiva e, assim, negando-lhes direitos.

Compreende-se a existência pública da categoria trabalhadora rural, com identidade e discursos, a partir do que Mota (2006) denomina de perspectiva da construção, pois considera o estabelecimento das mulheres rurais como categoria construída coletivamente numa produção de diferentes agentes sociais e práticas políticas intercaladas por experiências femininas de mulheres do campo.

Isso implica falarmos em processos de reconhecimento. Como aponta Woodward (2000), ao pensar as múltiplas posições do sujeito, as identidades são sempre inacabadas, em construção e históricas. A apresentação de um grupo social, as trabalhadoras rurais, encontrase situada num terreno social e político no qual a categoria ganha visibilidade e legitimidade ${ }^{7}$. Logo, ser mulher e trabalhadora rural é uma posição assumida politicamente e discursivamente na busca por direitos e empoderamento ${ }^{8}$.

\footnotetext{
${ }^{7}$ Concordo com Cordeiro (2006) que tanto a posição quanto o lugar são produtos sociais, pois, ser mulher trabalhadora rural não é uma essência rígida ou algo intrínseco às mulheres que vivem e trabalham na área rural. Ser mulher trabalhadora rural é uma posição assumida a partir do lugar no qual a pessoa se situa. A ênfase recai nos contextos interacionais e discursivos nos quais as mulheres se posicionam como trabalhadoras rurais.

${ }^{8}$ Para Deere e León (2002), o termo empoderamento remete ao conceito de poder enquanto relação social. Para as autoras, as relações de poder podem significar dominação, mas também um mecanismo de resistência. Desse modo, o poder condiciona a experiência das mulheres de duas maneiras: é fonte de opressão, mas também de emancipação. Dialogando com Jo Rowlands (1997), as autoras defendem a subdivisão do conceito de empoderamento em quatro formas: poder sobre, poder para, poder com e poder de dentro. O poder dentro referese ao poder interno, relacionado à geração de força de cada indivíduo. O poder para "serve para catalisar a mudança quando uma pessoa ou um líder de um grupo promove o entusiasmo e a ação de outros. É um poder gerador ou produtivo, um poder criativo ou facilitador que abre possibilidades e ações sem dominação", sendo, portanto, o oposto do poder sobre, onde o aumento no poder de alguém significa a perda de poder para outra pessoa. O poder para está relacionado ao poder com, pois pressupõe à ideia de um poder compartilhado. (DEERE e LEÓN, 2002, p. 54. Grifos no original)
} 
As trabalhadoras rurais brasileiras, durante o processo de abertura política do Brasil, enviaram várias cartas com sugestões à Assembleia Nacional Constituinte ${ }^{9}$. Esses documentos são fontes importantes para investigarmos questões relativas à condição feminina no campo brasileiro, principalmente no que diz respeito ao trabalho, como veremos adiante.

O Conselho Nacional dos Direitos da Mulher, criado em 1985, teve importância fundamental na luta para que as demandas das mulheres brasileiras fossem incorporadas à Constituição de 1988. Segundo Pitanguy (s/d) a campanha do Conselho pelos direitos das mulheres teve início em 1985, quando a estratégia de atuação foi elaborada: uma campanha nacional com os lemas "Constituinte Para Valer tem que ter Palavra de Mulher" e "Constituinte para Valer tem que ter Direitos da Mulher”. Grandes articulações nacionais foram feitas, envolvendo Conselhos Estaduais e Municipais de Direitos da Mulher, centrais sindicais e associações, procurando aproximar-se de diversas organizações de trabalhadoras, movimentos sociais e grupos feministas. $\mathrm{O}$ conselho chamava mulheres, tanto urbanas quanto rurais, a apresentarem propostas para a nova constituição.

As cartas abaixo, escritas e enviadas por Zelia Rigo, do Estado de Santa Catarina e Melânia Krindges, Rio Grande do Sul, nos auxiliam no processo de análise da emergência histórica e política da categoria "trabalhadoras rurais":

Líder dos trabalhadores rurais: as trabalhadoras rurais trabalham mais que os homens e não têm direito à aposentadoria. Trabalho na lavoura, em casa e ainda lavo roupa para fora, enquanto o homem fica descansando. Esperamos que isso mude com a nova Constituinte e a reforma agrária. Queremos aposentadoria aos 40 anos de idade porque nós é que temos que cuidar dos filhos, e não o marido. A aposentadoria do marido, não dá nem para ele quanto mais para a família. Nós mulheres, trabalhadoras rurais queremos aposentadoria ${ }^{10}$ (grifo nosso).

Como trabalhadora rural, há 20 anos diariamente lutando na roça ao lado de marido e filhos, contribuindo para o sustento e alimentação de tantos brasileiros e até hoje sem assistência nenhuma da previdência, sem aposentadoria e nem direitos de participação garantida. Isto porque até hoje a lei do Brasil nos discrimina e nós não somos reconhecidas como trabalhadoras rurais nos nossos documentos. Que a próxima constituição seja feita de direitos iguais para trabalhos iguais. Em nome da Comissão dos Trabalhadores Rurais da Regional da Grande Santa Rosa, onde coordeno a organização das mulheres rurais, nos 13 sindicatos de trabalhadores rurais, estamos firmes esperando que os nossos direitos entrem na constituição ${ }^{11}$ (grifo nosso).

\footnotetext{
${ }^{9}$ Uma das principais ações dos movimentos sociais foi o envio de cerca de 70 mil cartas e telegramas ao deputado Flávio Bierrenbach (PMDB), relator da Comissão Mista encarregada de dar o parecer ao projeto de convocação da Assembléia Nacional Constituinte.

${ }^{10}$ Carta de Zelia Rigo enviada à ANC.

ORIGEM: L016 DATA: 06/07/86 FORMUL: 399 DV: 3 TIPO: 10 05/02/87. Disponível em: http://www.senado.leg.br/atividade/baseshist/asp/detalheDocumento.asp?codBase=1\&codDocumento=42642\&s gBase=SAIC\&q=trabalhadoras+rurais. Acesso em 17 de julho de 2018 .

${ }^{11}$ Carta de Melânia Krindges enviada à ANC.
} 
Melânia escreveu outra carta, onde falou em nome da Comissão de Trabalhadoras Rurais do Sindicato dos Trabalhadores Rurais de Santo Cristo, Rio Grande do Sul.

A Comissão das Trabalhadoras Rurais do Sindicato dos Trabalhadores Rurais de Santo Cristo espera que os direitos da mulher trabalhadora rural entre na constituição em lei que são o reconhecimento da nossa profissão, os direitos de sindicalização, uma previdência justa com aposentadoria aos 50 anos de idade ou 30 anos de serviço com um salário mínimo, acidente de trabalho, auxílio doença, auxílio natalidade e salário modernizado, assistência médica gratuita. Reforma Agrária, política agrícola justa voltada para o pequeno agricultor. Direitos de inclusão do nome da esposa no bloco de produtor modelo 15. Mais garantia nos direitos humanos em defesa da família do agricultor. Que toda ela tenha proteção sem discriminação ${ }^{12}$ (grifo nosso).

A partir desses documentos é possível refletir sobre o posicionamento das mulheres trabalhadoras rurais em dois momentos, não isolados, mas atravessados: a centralidade das questões trabalhistas no processo político de posicionamento como trabalhadoras rurais e a conjuntura política do Brasil, terreno social dos movimentos sociais.

Partindo dos conteúdos das cartas e intencionalidade da escrita, é possível perceber como o reconhecimento profissional é o tema central no processo de construir-se como trabalhadora rural. A consciência de si como trabalhadora ganha existência pública no processo de luta para que o Estado legitime esta condição.

Para além do reconhecimento como trabalhadoras, as mulheres rurais reivindicavam a sindicalização e a disputa da direção dos Sindicatos dos Trabalhadores Rurais, aposentadoria, auxílio-acidente de trabalho, auxílio-doença, salário-maternidade, entre outros (SALVARO, LAGO e WOLFF, 2013, p. 81). Na luta por direitos trabalhistas e previdenciários emerge politicamente a categoria "Trabalhadoras Rurais". O que observamos é a centralidade que a categoria trabalho adquire nesse processo político de autoidentificação das trabalhadoras. As cartas citadas anteriormente corroboram essa afirmação e nos fornecem alguns elementos analíticos a esse respeito, o que investigaremos a seguir.

Havia, num primeiro momento, a necessidade de autoafirmação das mulheres do campo como trabalhadoras rurais. Essa urgência estava associada à vontade de desconstruir a concepção do trabalho feminino como ajuda ou complemento, pensando-o enquanto trabalho

ORIGEM:L010 DATA: 29/04/86 FORMUL: 237 DV: 4 TIPO: 10 17/12/86.

Disponível em:

$<$ http://www.senado.leg.br/atividade/baseshist/asp/detalheDocumento.asp? codBase $=1 \&$ codDocumento $=25584 \&$

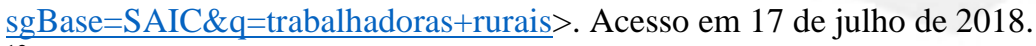

${ }^{12}$ Carta de Melânia Krindges enviada à ANC.

ORIGEM: L010 DATA: 29/04/86 FORMUL: 238 DV: 1 TIPO: 10 17/12/86. Disponível em:

http://www.senado.leg.br/atividade/baseshist/asp/detalheDocumento.asp?codBase $=1 \&$ codDocumento $=25585 \& \mathrm{~s}$ gBase=SAIC\&q=trabalhadoras+rurais. Acesso em 17 de julho de 2018. 
produtivo, conforme pode-se constatar nos trechos das cartas, citados anteriormente. As palavras de Melânia Krindges, falando em nome da Comissão das Trabalhadoras Rurais do Sindicato dos Trabalhadores Rurais de Santo Cristo, é exemplar, pois ela ressalta a necessidade do reconhecimento do trabalho das mulheres do campo como profissão.

Outro ponto presente nas cartas é a dificuldade para a comprovação da atividade profissional e como isso estava vinculado às implicações do não reconhecimento do trabalho na vida material das mesmas. Assim, não ser considerada trabalhadora tinha implicações concretas no cotidiano das mulheres e da família camponesa.

O que é denunciado nas cartas é o fato de que o não acesso à categoria trabalho resultava na negação de direitos, inclusive de sindicalização, e para acessá-los o processo de autoafirmação como trabalhadoras era a via fundamental. Logo, é o cenário das constituintes aliado ao enfrentamento histórico das mulheres do campo que torna possível o aparecimento das "mulheres trabalhadoras rurais" como sujeitos de discursos e de direitos.

Segundo Salvaro, Lago e Wolff (2013, p. 81), diante da complexidade que envolve a produção de determinada identidade política, é pertinente considerar que as reivindicações (e conquistas) das mulheres agricultoras pelo reconhecimento profissional e por direitos trabalhista-previdenciários se inserem em campos de disputas por reconhecimento cultural (na esfera da diferença, envolvendo demandas de gênero, étnicas) e redistribuição socioeconômica (na esfera da igualdade).

Estas questões levantadas deram visibilidade e oficialidade ao trabalho das mulheres agricultoras. Ao lutar por direitos sociais, emerge uma nova identidade: a de mulher trabalhadora rural enquanto novo sujeito político.

A emergência do movimento de mulheres trabalhadoras rurais sugere um deslocamento no status quo. Ao se manifestarem em relação a questões relacionadas às suas vivências cotidianas elas romperam um silêncio que lhes é continuamente imposto e utilizaram-se de um lugar de fala usualmente acessado pelos homens e naturalizados como masculinos.

O campo brasileiro historicamente projetou-se como espaço da autoridade masculina, o que acarretou, entre outros aspectos, na desvalorização do trabalho das mulheres nesse espaço ${ }^{13}$. No campo, havia (há) uma leitura que considera que o homem trabalha e esposa e filhos o ajudam. Essas noções estão presentes nas cartas enviadas à ANC por Zélia Rigo, por exemplo, ao apontar que "trabalha na lavoura, em casa e ainda lavando roupa para fora", ela procura denunciar a invisibilidade e a falta de reconhecimento da tripla jornada de trabalho. Para

13 A respeito da desvalorização do trabalho das mulheres no campo brasileiro, ver: HEREDIA; GARCIA; GARCIA JR.,1984; ESMERALDO, 2013; PAULILO, 1987. 
Esmeraldo (2013), essa desvalorização está relacionada à posição do homem como chefe de família e provedor da casa.

No Brasil, a posicionalidade de mulher trabalhadora rural insere-se na conjuntura política e histórica que remonta ao processo de redemocratização, resistências camponesas e avanço das pautas feministas. A afirmação dessa posição se entrelaça à uma conjuntura marcada pelo entusiasmo e esperança da década de 1980, manifesta pela emergência de novos atores que entraram em cena nos anos finais da década de 1970.

Segundo Habert (1992), o fim da década de 1970 foi extremamente significativo na busca pelos direitos das minorias, promovendo manifestações públicas, organizando-se em entidades e promovendo debates sobre tais questões. Habert (1992, p. 73) assim define a importância dos anos finais da década de 1970 para as mulheres:

Desenvolvendo uma ação mais direta e organizada, os movimentos feministas combinaram a luta contra a ditadura e por melhores condições de vida com a discussão dos problemas específicos das mulheres - a sexualidade, o controle da concepção, o aborto, o prazer sexual, a dupla jornada, a discriminação econômica, social e política.

Unindo-se aos mais diversos movimentos (negro, homossexual, sindical, entre outros), as mulheres expressavam as insatisfações com as condições imperantes. Desse modo, diferentes movimentos sociais (re) organizaram-se na década de 1980.

Gaspareto e Menezes (2013) ao analisarem a constituição do Movimento de Mulheres Agricultoras em Santa Catarina, indicam a década de 1980 como início dessa organização, entre outros fatores, pelo fato de esse período ser marcado por atuações de diversos movimentos e organizações religiosas como: Comunidades Eclesiais de Base, Comissão Pastoral da Terra, pastorais sociais, associações, sindicatos, Movimento dos Trabalhadores Sem Terra (MST, Movimento dos Atingidos pelas Barragens (MAB), além de Sindicato de Trabalhadores Rurais.

As primeiras organizações de mulheres trabalhadoras rurais surgiram em $1982^{14}$ no sertão pernambucano e no interior do sul do país, e no acompanhamento socioetnográfico do cotidiano da militância do Coletivo Estadual de Mulheres da Federação dos Trabalhadores e Trabalhadoras Rurais do Ceará (FETRAECE), e do Movimento de Mulheres Trabalhadoras Rurais (MMTR) (MOTA, 2006, p. 342).

\footnotetext{
${ }^{14}$ Essa década foi importante para a organização das mulheres trabalhadoras rurais, desencadeadas pelas demandas de reconhecimento profissional de suas atividades. Tal fato não implica, porém, que a mulher estivesse ausente das lutas travadas por camponeses e trabalhadores rurais em momentos anteriores. Observa-se, nessa época, uma mudança na qualidade desta participação. A participação de mulheres em movimentos sociais no campo toma uma característica singular nesse momento, onde são realizados os primeiros encontros voltados para problemas que lhes são específicos. Até então, a inserção feminina nos movimentos sociais no campo realizava-se, normalmente, através da participação dos respectivos maridos ou de outros familiares (CARNEIRO, 1994).
} 
Através da participação em tais espaços, as mulheres do meio rural foram articulando elementos como discursos, práticas, imagens, narrativas, identidades, todos circunstanciados por tensões, conflitos, estratégias, emoções, rituais que realçavam um processo de fabricação, de produção coletiva, que ao longo do processo foi tomando a forma de uma construção - a construção sociológica das mulheres trabalhadoras rurais como categoria política (MOTA, 2006, p. 342).

Nesse processo, a inserção nos Sindicatos Rurais foi uma estratégia de expressão e luta pela valorização do trabalho feminino. Entretanto, o processo histórico dessa inserção é marcado por obstáculos, pois como apontou Boni (2004), historicamente construídos enquanto espaços do fazer político, os sindicatos rurais afirmam-se como lugar masculino.

Segundo a autora, que analisou a realidade de Chapecó (SC), até o início dos anos 1980 não era comum mulheres associadas aos sindicatos. Conforme afirma, pouquíssimas mulheres que se associavam ao órgão sindical rural, pois aquelas que eram casadas eram consideradas dependentes do marido e as solteiras dependentes do pai, não havia incentivos para sindicalização e participação visto que não eram consideradas agricultoras, mas esposas de agricultor.

\section{Sindicalização: um caminho para a organização política e direitos}

A percepção da relação de dependência e não reconhecimento do trabalho das mulheres era um obstáculo para a sindicalização, conforme destacado anteriormente. As narrativas da trabalhadora rural e sindicalista, Sra. Zenóbia Cedorak de Godoy, que analisaremos na sequência, sobre a inclusão e participação das mulheres no Sindicato dos Trabalhadores Rurais de Pitanga, região Central do Paraná, apesar de localizada, reporta a um conjunto de mobilizações de diferentes segmentos de mulheres do campo brasileiro nos sindicatos rurais, nas últimas décadas do século XX.

Constituído formalmente em janeiro de 1984, na conjuntura de abertura política no Brasil, o Sindicato dos Trabalhadores Rurais de Pitanga era formado, em sua maioria por pequenos proprietários rurais e trabalhadores sem terra. Mobilizava-se, principalmente, pela reivindicação de Reforma Agrária, já que a região era/é marcada por elevada concentração de terras, e lutava pelo fim da exclusão social e exploração de trabalhadores/as rurais, acentuada pela modernização agrícola.

Enquanto organização de trabalhadores, no masculino, incorporava grupos (sem-terra, pequenos proprietários, arrendatários, boias-frias, posseiros, meeiros) aos quais se aplicava a 
categoria trabalho. Nessa perspectiva, as mulheres situavam-se noutro plano: do não trabalho e/ou trabalho reprodutivo e, desse mesmo modo, a hierarquia nas relações de trabalho na unidade doméstica se reflete no espaço sindical rural.

A narrativa da Sra. Zenóbia manifesta as nuances do trabalho das mulheres na região e período estudado:

\begin{abstract}
Ah, as mulheres iam pra roça, sim! [...] a maioria das mulheres, praticamente no geral, elas enfrentavam a lida diariamente com os homens. Era carpir, roçar, ajudar nas colheitas, era muito feijão que se plantava, né? E elas iam junto, além da atividade doméstica elas tinham esse outro trabalho que era juntamente com os homens na roça, até tinha um grupo de mulheres que elas pegavam empreitada, carpida, né? Carpiam por empreita, milho, feijão. Elas enfrentavam de cedo à noite [...] A maioria deixava o trabalho de casa só para o final de semana, para o sábado e domingo, pra dar conta da roupa limpa, da casa, tudo. Enfrentavam de segunda a sexta o trabalho na roça (GODOY, 2015).
\end{abstract}

As percepções da Sra. Zenóbia excedem o plano individual/particular e adentram num âmbito mais coletivo. A narrativa dimensiona as inúmeras atividades desenvolvidas pelas mulheres, principalmente as mais pobres, no campo do sul do Brasil. Mesmo trabalhando em pé de igualdade com os homens na roça, local de autoridade masculina, não eram reconhecidas juridicamente e socialmente como trabalhadoras.

Essa invisibilidade do trabalho pode ser pensada também a partir das fontes da pesquisa, pois, ao iniciar o estudo sobre as trabalhadoras rurais dessa região constatei que os documentos anteriores à década de 1990 traziam a profissão das mulheres como do lar, já a categorização profissional dos homens era a de agricultor. Ou seja, o trabalho feminino não era considerado produtivo.

No universo camponês o que é considerado trabalho produtivo e trabalho improdutivo? São conceitos relacionados às atividades consideradas econômicas e não econômicas, separados por uma conjuntura capitalista que dissociou espaço doméstico de espaço de produção, procurando subordinar a sociedade ao mercado. E assim, segundo Paulilo (2004, p. 244), o único esforço físico ou mental que passou a merecer o nome de trabalho produtivo e a ser remunerado foi o despendido nas atividades consideradas econômicas, em que se extraem a mais valia ${ }^{15}$. Desse modo, historicamente, o trabalho das mulheres do campo, seja qual for a sua dificuldade ou peso, é marcado pelo caráter de improdutivo ou reprodutivo.

\footnotetext{
${ }^{15}$ Segundo Paulilo (2004), não é fácil visualizar esse pressuposto no campo, visto que no campesinato a unidade familiar e de produção se confundem. A autora também aponta o problema de se explicar a forma de produzir camponesa pelos parâmetros de um modo de produção capitalista, o que faria sentido, se o entendimento do campesinato carregasse a significação de extinção ou adequação à sociedade moderna.
} 
Os espaços de gênero, observados na região estudada, facilmente podem ser definidos a partir da simbólica desenvolvida por Woortmann e Woortmann (1997, p. 134-135) nos sítios camponeses do nordeste brasileiro: "Nas construções ideológicas dos sitiantes existem dois circuitos de atividades, o masculino e o feminino. No plano mais amplo, tudo que diz respeito ao pasto e a roça é circuito masculino; o que diz respeito à casa ${ }^{16}$ é feminino".

$\mathrm{Na}$ concepção dos pesquisadores citados acima, o trabalho no campo não é produtor apenas alimentos, mas também (re) produz ideias. A partir desse trabalho se consegue interpretar a lógica camponesa da hierarquia de gênero. A subordinação da mãe e dos filhos ao chefe de família (pai) é baseada no saber-fazer. É o pai que domina esse saber, governa o trabalho a partir de um saber técnico que produz um saber simbólico e que, portanto, justifica a reprodução da estrutura social de gênero. O poder exercido pelo pai de família legitima-se pelo domínio do saber-fazer, fundamental para a reprodução da unidade camponesa.

O encadeamento de ações que envolvem o entendimento camponês sobre a concepção de trabalho - e que cria espaços de gênero evidentes - têm seus significados estendidos para o interior da entidade sindical rural. Para as trabalhadoras rurais, o trabalho nas múltiplas atividades, incluindo o trabalho na agricultura, apesar de exigir tanto, não foram impedimentos para a participação nos debates e militância política no sindicato. Tradicionalmente cobradas pelas atividades relacionadas ao doméstico, considerado seu domínio, a conciliação dessas múltiplas atividades com a prática política no espaço sindical não era tarefa fácil.

A perspectiva de que são os homens que trabalham e as mulheres apenas ajudam dificulta a inserção das mulheres no espaço sindical. Isso explica o esforço das mesmas para a mudança estatutária que as qualificava enquanto do lar para trabalhadoras rurais ou agricultoras. Como veremos, as práticas de reprodução social do campesinato e as distinções espaciais de gênero são, de certa maneira, atualizadas no sindicato rural.

A instrumentalização política das trabalhadoras se inicia nas discussões dos Círculos Bíblicos. Nesses espaços, levantava-se questionamentos sobre a condição da classe trabalhadora rural. As questões abordadas faziam parte do que a Sra. Zenóbia denominou de

\footnotetext{
${ }^{16}$ Considerando que o lugar que homens e mulheres ocupam na unidade doméstica camponesa está relacionado às atividades que desenvolvem na casa ou na roça, é importante definir o que o espaço da casa significa, em termos de trabalho. Casa não se restringe ao espaço material das paredes da residência da família. Nossa interpretação apoia-se nos pressupostos de Heredia, Garcia e Garcia Jr (1984, p. 31) analisando o caso na região nordeste brasileiro, os quais dizem: "A casa não se restringe ao espaço físico ocupado pela construção; ela inclui também o terreiro (pátio) que a rodeia, local onde vive a criação (aves de quintal), cabras e porcos. O conjunto desses animais é denominado animais de quintal, aludindo ao espaço em que se criam. Atividades que esses animais exigem são também, como a casa, responsabilidade feminina e não reconhecidas como trabalho". A divisão de tarefas por sexo é o que dá sentido à oposição feminino e masculino. Tanto nos estudos de Heredia, Garcia e Garcia Jr (1984) quanto nas análises de Woortman e Woortman (1997), o que é considerado trabalho liga-se as atividades desenvolvidas pelos homens.
} 
luta maior, logo, questões relacionadas às especificidades das mulheres do campo não eram problematizadas.

Essa mesma prática, como veremos, era visualizada no interior do Sindicato Rural de Pitanga. As memórias da Sra. Zenóbia indicam que as dificuldades para participarem das reuniões sindicais se iniciavam em casa. Colocando-se enquanto exceção que confirma a regra, ela manifesta aspectos desse imaginário social camponês:

[...] meu marido tinha muito orgulho de ver a gente participando do sindicato [...] muitas mulheres não conseguiam participar, justamente por isso, não tinham apoio em casa. Não era comum a visão que meu marido tinha, era muito raro, depois foi se abrindo, mas no início era difícil mesmo, tinha muitas companheiras que gostariam de ir, mas o marido não deixava, porque tinha de ficar em casa, tinha de ir pra roçajunto, tinham aquele bando de filhos. As mulheres, na época, no sítio tinham muitos filhos, cinco, seis, dez filhos, então ficava em torno da família e não conseguia participar. Na comunidade tinha várias, tinha uma tia minha, que ela participava da igreja, da igreja ela conseguiu que o marido deixasse ela participar, muito mais tarde ela conseguiu a libertação, mas no início o marido não deixava de jeito nenhum. Tinha um compadre nosso, ele era atuante e tudo, apoiava, mas na hora da esposa ir, não deixava, porque ela tinha os afazeres em casa, ele dizia. E as que participavam, decerto não tinham? Ma as dele tinha os afazeres em casa, esse casal aí tinha um atrito muito grande por causa disso, né? Até na questão da própria comunidade, na organização, ela não ia trabalhar porque o marido não deixava, ela queria, mas tinha de ficar em casa e ele que participava, fazia parte até das comissões. Depois as coisas mudaram, o sindicato ajudou nisso, o Osmano falava nas comunidades (GODOY, 2015).

A rigidez da configuração social dos espaços, que associava as mulheres a papéis tradicionais familiares era legitimada pela concepção do espaço doméstico como lugar natural das mulheres. A prescrição cultural do período definia o lugar da mulher na sociedade. A hierarquia é baseada na autoridade masculina sobre a mulher, o que regula a configuração dos espaços e a mobilidade das mulheres. O número de filhos, o fato de ser mãe de família e o trabalho no campo eram fatores acionados como empecilhos para a participação nas discussões do sindicato.

Ao longo dos anos, após sua fundação em 1984, o número de mulheres participantes aumenta, ao que parece, o amplo trabalho de base desenvolvido pelo próprio sindicato amparados e legitimados pelos discursos da Central Única dos Trabalhadores (CUT), Comissão Pastoral da Terra (CPT) e Partido dos Trabalhadores (PT) - acaba por desenvolver certa consciência de gênero entre homens e mulheres.

O relatório de reuniões de 23 de janeiro de 1985 mostra que após extensa discussão sobre os problemas econômicos que afetavam os agricultores da região, como o baixo preço dos produtos agrícolas, a Reforma Agrária e a exploração do homem do campo foi mencionada 
a problemática da participação das mulheres: "Será estudado futuramente a participação da mulher dentro da comunidade e sindicato" (ATAS, Reuniões nas comunidades do município de Pitanga, 1985).

A Sra. Zenóbia valoriza a figura pública do presidente do sindicato, Osmano Soares dos Reis, uma das principais lideranças no processo de fundação sindical. Para ela, a interferência dele foi fundamental para que a participação acontecesse. Entretanto, segundo ela: "[...] havia companheiros que olhavam atravessado" (GODOY, 2015). Isso indica que a aprovação da presença feminina não era unânime.

Predominava no espaço sindical a percepção do feminino atrelado ao doméstico. Ao tratar da organização das mulheres, os papéis tradicionais de mães e esposas são acionados.

Como verifiquei nos registros escritos do sindicato, a denominação de Movimento de mães e esposas trabalhadoras rurais é comum ao tratar da organização feminina no seu interior. O resguardo da representação das trabalhadoras ligadas ao lar, aos cuidados familiares passava a ser entendido como defesa da presença feminina em um lugar tido como não natural às mulheres. Nessa perspectiva, o entendimento era de que a saída de seu lugar natural era legitimado pela vontade feminina de proteger e cuidar da família ${ }^{17}$.

Portanto, são as classificações sociais de masculino e feminino que orientam a entrada e a permanência das trabalhadoras no espaço masculino sindical. Isso também é evidenciado nas principais áreas em que as mulheres atuavam, conforme destaca a entrevistada:

No sindicato, a gente atuava mais assim, nas questões de saúde, saúde e educação eram temas fortes, aí depois começou a vir os direitos da mulher trabalhadora, né? Aposentadoria da mulher, licença maternidade pra mulher da roça, auxílio doença pra agricultora, daí nós trabalhava nessas questões também, que eram mais necessárias [...] essa questão das mulheres, na época era muito precária (GODOY, 2015).

A narrativa indica que as principais atuações das trabalhadoras dentro do sindicato estavam ligadas, ao menos inicialmente, à saúde e educação, atividades de cuidado, que a percepção do período entendia como coisa de mulher, relacionados à sensibilidade, calma, solidariedade, piedade, atributos entendidos como virtudes naturais das mulheres. Nessas áreas

\footnotetext{
${ }^{17}$ Esmeraldo (2013, p. 248-249), ao analisar a lógica dos movimentos rurais, enfocando as ações políticas dos trabalhadores Sem Terra, diz que: "Internamente, o que mobiliza o comparecimento das mulheres às manifestações e lutas no campo é a compreensão da necessidade da presença de toda a família nas mobilizações; é a expressão do sentido familiar que move o modo de vida e de produção da agricultura camponesa; é a representação das mulheres como membro da família camponesa nos seus papéis de esposas, mães, gestantes e filhas de camponeses na luta por terra e trabalho livre e os seus desejos e disposições em garantir a sobrevivência da família". É o entendimento de família que orienta a saída das mulheres para os espaços de luta.
} 
de atuação os papéis sociais das mulheres são reformulados, suas novas funções são pensadas como extensões daquelas ligadas ao cuidado da família.

A socialização das mulheres para a esfera privada e mesmo a tentativa de estendê-la à esfera pública não impede que elas se engajem na luta pelo reconhecimento de seu trabalho e direitos. Reivindicações por afirmação política enquanto Mulheres Trabalhadoras Rurais ou agricultoras é constante nas ações e discursos das trabalhadoras.

O trabalho de base ${ }^{18}$ desenvolvido pelo Sindicato rural nas várias e distantes comunidades rurais do município adentrava os lares e sinalizava para um novo momento das relações de gênero. A organização sindical rural, incluída no que Gohn (2003) denominou de Novos Movimentos Sociais, denota a vontade de combater práticas discriminatórias, anuncia o novo para os homens e mulheres do campo.

Apesar disso, como vimos, é possível constatar práticas discriminatórias no seu interior e, sobre os cargos ocupados pelas mulheres no sindicato, a entrevistada afirmou:

Não era coisa comum, na época, as mulheres ocuparem cargo de direção. Tanto é que mulher presidente de alguma coisa era difícil né? Ainda mais no sindicato, geralmente a gente ficava lá [...] então, geralmente os cargos maiores, de presidente ou tesoureiro eram coisas de homens, né? Não, presidenta não tinha não. Aqui em Pitanga nunca teve mulher na presidência do sindicato [...] (GODOY, 2015).

A ausência das trabalhadoras nos cargos de liderança sinaliza para um modelo sindical pautado na autoridade masculina. Desde sua fundação em 1984 até os dias atuais nenhuma mulher ocupou cargo na presidência. Além de serem minoria nesses espaços, as funções ocupadas por elas eram as consideradas menos importantes. A própria entrevistada enfatiza esse pressuposto: "Eu, por exemplo, era secretária, nunca passei disso" (GODOY, 2015).

\footnotetext{
${ }^{18} \mathrm{O}$ trabalho de base consistia num conjunto de práticas de conscientização, formação e atuação política, desenvolvidas pelo STRP nas comunidades rurais de sua abrangência. O Sindicato dos Trabalhadores Rurais de Pitanga desenvolveu um amplo trabalho de base, investindo na construção de sentido de classe social. Dentre as suas atividades, estão visitas às comunidades rurais, onde se discutia o trabalho e função do sindicato, principalmente com relação à política agrícola, também organizava associações comunitárias. No mesmo ano de sua constituição, 1984, um pedido de ajuda ao CERIS (Centro de Estatísticas Religiosas e Investigações sociais), elaborado pelo STRP, diz: "Após a data de fundação para cá já visitamos 64 comunidades, sentindo nessas visitas todos os problemas da classe trabalhadora: como falta de assistência médica, falta de preços, poceiros sendo expulsos de suas posses, crianças e mulheres marginalizadas nas fazendas, falta de conhecimentos dos direitos humanos, etc. e já contamos com aproximadamente 1000 sócios [...] As dificuldades que estamos enfrentando: É a continuação e ampliação deste trabalho de base nas comunidades, esta ampliação é muito necessária por que a cada dia que passa crescem os problemas e surge mais necessidades da classe se organizar[...] muitos agricultores estão desanimando em viver na agricultura, sentimos que com o nosso apoio desperta-se o interesse em continuar na terra. Muitos trabalhadores rurais ainda não sabem o que é o sindicato e para que serve. Estamos despertando a consciência da união da classe [...]" (Pedido de ajuda ao CERIS- Centro de Estatísticas Religiosas e Investigações Sociais. A História da caminhada do Sindicato dos Trabalhadores rurais de Pitanga. 01 de novembro de 1984, p. 1. Disponível no Sindicato dos Trabalhadores Rurais de Pitanga).
} 
Aparentemente consideradas menos aptas à liderança, a secundarização do trabalho das mulheres na agricultura estende-se às funções sindicais. A Sra. Zenóbia indica discursos e práticas de rebeldia das trabalhadoras: "Nós muitas vezes dissemos: nós não estamos aqui só para lavar louças, fazer comida pra vocês, nós queremos participar” (GODOY, 2015). Suas palavras manifestam a tentativa de reafirmação do que entendiam como lugar de mulher. No universo de representações, lavar louças e fazer comida são atividades naturalmente femininas. Essa prática reforçava a ligação das mulheres aos seus papéis tradicionais de mães e esposas e procurava afastá-las das discussões políticas.

O empenho delas na tentativa de desvencilhar-se desse estereótipo é consubstanciado no questionamento desses lugares, demonstrando o desejo de participarem efetivamente das discussões. Para as trabalhadoras, mesmo no espaço público, o privado se reedita ${ }^{19}$.

$\mathrm{Na}$ compreensão do processo de ressignificação dos espaços dentro do sindicato, a interpretação de Woortmann e Woortmann (1997, p. 63) sobre a dicotomia rua-casa e frioquente no imaginário social é fundamental:

A rua é um domínio frio, do homem, que para nele vencer na vida deve agir de maneira racional, equilibrada. A casa é um lugar que deve ser quente. Nela deve haver calor 'humano'; a racionalidade fria deve ceder lugar a afetividade quente, e a mulher dona da casa deve imprimir tal 'clima'.

O imaginário de um distanciamento das mulheres da racionalidade que o espaço público exige as desqualifica, tal perspectiva caminha para reafirmação das mulheres como seres afetivos e irracionais. Nessa análise, verificamos que nesse imaginário naturalizante, o lar era o lugar adequado para mulher e o político inadequado.

Questionada sobre o envolvimento do sindicato rural sobre as questões específicas das mulheres, a Sra. Zenóbia diz que "houve momentos que a gente discutia, sabe? Discutia sim, mas na maioria das vezes era no geral, mas houve momentos que nós discutíamos questões mais específicas [...] só que a prioridade era as de classe" (GODOY, 2015).

A prerrogativa de que a luta das mulheres estava incluída na luta geral ou maior é constante no discurso sindical ${ }^{20}$. A violência doméstica, por exemplo, era vista como algo que

\footnotetext{
${ }^{19}$ Os termos público e privado, de acordo com Okin (2008), vão além da dicotomia doméstico e não doméstico. Reconhecemos que o poder político não é unicamente aquele que opera fora dos limites da casa; a divisão do trabalho, os laços de dependência econômica e as táticas individuais de negociação na unidade camponesa relacionam-se a essa estrutura de poder. Entendemos o caráter político da família camponesa, entretanto, as expressões utilizadas no texto dizem respeito à sociedade e ao Estado. Para além de discutir sobre o caráter político da família camponesa, nossa análise entende a separação do público e não público como resultado de distinções prévias patriarcais que associou homens ao econômico e político e as mulheres à domesticidade e reprodução.

${ }^{20}$ Sobre as questões de classe e de gênero dentro dos sindicatos rurais, Movimento dos Trabalhadores Sem Terra (MST) e Movimentos Autônomos de Mulheres, na lógica dos Estados do sul do país, Paulilo (2004) afirma que
} 
deveria ficar em casa, pois era de domínio privado. A Sra. Zenóbia aponta que violência sofrida na militância (público) chegava a ser debatida no sindicato. Havia uma fronteira política que definia o que era assunto público e o que não era. As violações sofridas pela causa política de classe, fora do âmbito doméstico, era assunto de discussão, a violência doméstica, ao contrário, era de domínio privado e pessoal, ou seja, deveria ser resolvida em casa.

O sindicato incorpora fortemente a luta das mulheres pelo reconhecimento como trabalhadoras rurais e, por conseguinte, a inclusão nos direitos previdenciários, como aposentadoria, licença maternidade, auxílio doença, entre outros. Sugere-se que se entendia que tais questões, para além do caráter individual, diziam respeito às relações econômicas de classe, pois beneficiariam o conjunto da família camponesa.

Nesse contexto, apoiaram um grande passo para a superação do caráter de improdutivo das atividades das mulheres do campo: a mudança no estatuto para trabalhadoras rurais. Nas palavras da Sra. Zenóbia:

Essa conquista de mudar para agricultora foi uma luta das mulheres, nossa. O movimento de mulheres que puxou e conseguiu aprovar essa lei. Algumas companheiras que foram eleitas também, na época, para o senado e tal, aí conseguiram aprovar, reconhecer a mulher enquanto agricultora, enquanto profissão, para garantir os direitos, né? Daí melhorou bastante, nossa, deu mais autonomia pra mulher. Essa conquista foi muito importante, nós lá da comunidade, ajudamos muitas a se aposentar. Eu lembro daquelas velhinhas, como elas ficaram faceiras. Nossa, até moradia começou a melhorar, sabe? O aspecto físico das mulheres começou a mudar, a gente não precisava mais pedir dinheiro pra marido pra comprar um batom ou um esmalte (GODOY, 2015).

$\mathrm{O}$ direito das mulheres à aposentadoria por idade, aos 55 anos, e alguns outros benefícios, foi assegurado pela constituição de 1988. A fala da entrevistada sobre os significados que a mudança no estatuto representou para as trabalhadoras de sua comunidade associa a autonomia à conquista dos direitos trabalhistas, principalmente a aposentadoria. Isso mostra o quanto o alicerce financeiro é fundamental no processo de empoderamento das mulheres camponesas.

Essa modificação estatutária de do lar para trabalhadoras rurais, ocasionou modificações tanto no âmbito do empoderamento como no cenário camponês. A autonomia, apontada pela entrevistada, reflete numa transformação da sua imagem para si própria e perante a sociedade. O reconhecimento de seu estatuto profissional é considerado pela entrevistada como um passo na conquista por cidadania das mulheres do campo.

nos movimentos que colocam a luta de classes em primeiro lugar, o modelo de participação política é machista. Segundo ela, o discurso de igualdade de gênero é consenso, mas não se discute quão desigual é essa igualdade. 
Paulilo (2004), ao analisar os pressupostos das mulheres do campo e os movimentos sociais, diz que é difícil falar em reconhecimento sem estabelecer uma ligação com qualquer forma de suporte financeiro. A desigualdade econômica da mulher reflete na subordinação diária no interior da unidade doméstica.

Nos depoimentos da Sra. Zenóbia foi possível verificar que a conquista por direitos sociais, principalmente a aposentadoria, positivou o trabalho das mulheres e isso repercutiu, de certo modo, na relação familiar cotidiana, estabelecendo pequenos deslocamentos nas tradicionais relações de convivência, principalmente com relação ao companheiro/marido.

\section{Considerações finais}

Procurei discutir uma visão mais ampla do processo de construção da categoria Trabalhadora Rural, mas também mostrar, de forma mais localizada, como essa discussão se articulava no interior dos Movimentos Sociais Rurais, especificamente no Sindicato de Trabalhadores Rurais de Pitanga. Desse modo, ao analisar os contextos da inserção das trabalhadoras rurais nas discussões políticas sindicais, procurei examinar também a racionalidade camponesa e a lógica que orienta a divisão sexual de trabalho no campo.

Vimos que a inserção feminina no espaço político sindical não significa necessariamente o desmantelamento dos papéis e hierarquias sociais no seu interior. Alguns motivos são indicativos: (a) trata-se de uma participação autorizada; (b) essa participação é fundamentada pelo caráter de mães e esposas que atuavam na defesa do lar; (c) a hierarquia de funções designava as mulheres às funções subalternas, afastando-as dos cargos de liderança; (d) $\mathrm{O}$ caráter secundário de suas pautas no contexto da luta sindical rural.

Para Pedro (2000), poucas mulheres têm se aventurado no espaço político, são poucas as que se candidatam para cargos públicos, estes ainda tem sido um espaço do fazer masculino. Essa dificuldade de inserção das mulheres no campo político - até mesmo uma inserção marginal - reflete a concepção de que o espaço privado ainda é considerado e desenhado como o único lugar das mulheres. Apesar de certa mudança nos padrões culturais, a superação dessa racionalidade ainda é uma luta constante das mulheres e dos movimentos feministas.

Neste sentido, as mulheres do campo brasileiro subverteram um processo histórico de silenciamento e exclusão e desempenharam um papel fundamental na luta por direitos. Esta mobilização política marcou a prática do sindicalismo rural no país, introduziu neste espaço às problemáticas relacionadas às questões de gênero, reivindicando um olhar mais atencioso dos Movimentos sociais, poder público e da sociedade para as mulheres e o campesinato. 
Portanto, as discussões apresentadas foram pensadas a partir de concepções que consideram as relações de gênero e suas implicações no espaço rural, verificando o imaginário presente nas relações sociais entre homens e mulheres e percebendo as diferenças entre os sexos como construção.

\section{Referências bibliográficas}

AMADO, Janaína. O grande mentiroso: tradição, veracidade e imaginação em história oral. Revista de História Universidade Estadual Paulista, São Paulo, v. 14, 1995. Disponível em: $<$ http://www2.fct.unesp.br/docentes/geo/necio_turra/PPGG\%20\%20PESQUISA\%20QUALI $\%$ 20PARA\%20GEOGRAFIA/AMADO \%20-\%200\%20grande\%20mentiroso.pdf>. Acesso em: 15 jan. 2019.

BESSIN, Marc. Política da presença: as questões temporais e sexuadas do cuidado. In: ABREU, Alice Rangel Paiva [et. al.] (Orgs.). Gênero e trabalho no Brasil e na França: perspectivas interseccionais. São Paulo: Boitempo, 2016, p. 235-245.

BONI, Valdete. Poder e igualdade: as relações de Gênero entre sindicalistas rurais de Chapecó, Santa Catarina. Estudos feministas, Florianópolis, v. 12, n.1, p. 289-302, 2004.

CARNEIRO, Maria José. Mulheres no campo: nota sobre sua participação política e a condição social de gênero. Estudos sociedade e agricultura. Rio de janeiro, v.1, n.2, p. 1122, jun, 1994.

CORDEIRO, Rosineide de Lourdes Meira. Além das secas e das chuvas: os usos da nomeação Mulher trabalhadora rural no sertão de Pernambuco. In: WOORTMANN, Ellen Fensterseifer; HEREDIA, Beatriz; MENASHE, Renata. (orgs.). Margarida Alves: coletânea sobre estudos rurais e de gênero. Brasília: Ministério do Desenvolvimento Agrário, 2006.

DEERE, Carmem Diana; LÉON, Magdalena. O empoderamento da mulher. Porto Alegre: Editora da UFRGS, 2002.

ESMERALDO, Gema Galgani Silveira Leite. O protagonismo político de mulheres rurais por seu reconhecimento econômico e social. In: NEVES, Delma Pessanha; MEDEIROS, Leonilde Servolo. (orgs.). Mulheres Camponesas: trabalho produtivo e engajamentos políticos. Niterói: Alternativa, 2013.

GASPARETO, Sirlei; MENEZES, Marilda. As jovens do Movimento de Mulheres Camponesas (MMC) em Santa Catarina. In: NEVES, Delma Pessanha; MEDEIROS, Lonilde Servolo. (orgs.). Mulheres Camponesas: trabalho produtivo e engajamentos políticos. Niterói: Alternativa, 2013.

GOHN, Maria da Glória. Movimentos sociais no início do século XXI: antigos e novos atores sociais. Petrópolis: Vozes, 2003.

HABERT, Nadine. A década de 70: apogeu e crise da ditadura militar brasileira. São Paulo: Editora Ática, 1992.

HEREDIA, Beatriz Maria Alasia de; GARCIA, Marie France; GARCIA JR. Afrânio Raul. O lugar da mulher em unidades camponesas. In: AGUIAR, Neuma. (org.). Mulheres na força de trabalho na América Latina: Análises qualitativas. Rio de Janeiro: Vozes, 1984.

HIRATA, Helena; KERGOAT, Danièle. Novas configurações da divisão sexual do trabalho. Cadernos de Pesquisa, v. 37, n. 132, p. 595-609, set/dez. 2007.

JANY-CATRICE, Florence. Economia do cuidado e sociedades do bem viver: revisitar nossos modelos. In: ABREU, Alice Rangel Paiva [et. al.] (Org.). Gênero e trabalho no Brasil e na França: perspectivas interseccionais. São Paulo: Boitempo, 2016, p. 267-275. 
MONTENEGRO, Antônio Torres. Rachas as palavras. Ou uma história a contrapelo. Estudos Ibero-Americanos, Porto Alegre, n. 1, p. 37-63, jun. 2006.

MOTA, Maria Dolores de Brito. Margaridas nas ruas: as mulheres trabalhadoras rurais como categoria política. In: WOORTMANN, Ellen Fensterseifer; HEREDIA, Beatriz; MENASHE, Renata. (orgs.). Margarida Alves: coletânea sobre estudos rurais e de gênero. Brasília: Ministério do Desenvolvimento Agrário, 2006.

OKIN, Suzan Moller. Gênero, o público e o privado. Estudos feministas, Florianópolis, v. 16, n. 2, p. 305- 332, mai./ ago., 2008.

PAULILO, Maria Ignez. O peso do Trabalho Leve. Revista Ciência Hoje, Rio de Janeiro, vol. 5, n. 28, p. 64-70, 1987.

PAULILO, Maria Ignez. Trabalho familiar: uma categoria esquecida de análise. Estudos Feministas, Florianópolis, v. 12, n. 1, p. 229-252, jan./ abr. 2004.

PEDRO, Joana Maria. As mulheres e a separação das esferas. DHI/UEM, Diálogos, Maringá, v.4, n.4, p. 33-39, 2000.

PEDRO, Joana Maria. Traduzindo o debate: o uso da categoria gênero na pesquisa histórica. História, São Paulo, v. 24, n.1, p. 77-98, 2005.

PINSKY, Carla Bassanezi. Estudos de gênero e história social. Estudos feministas, Florianópolis, v. 17, n.1, p. 159-189, 2009.

PITANGUY, Jacqueline. As Mulheres e a Constituição de 1988. Disponível em $<$ http://mgstudio.com.br/clientes_mg/cepia/wp-content/uploads/2017/11/nov089.pdf> Acesso em 16 de julho de 2018.

POLLAK, Michael. A gestão do indivíduo. Web Mosaica Revista do Instituto Cultural Judaico Marc Chagall, Porto Alegre, v.2, n.1, p. 9-49, jan-jun. 2010.

PORTELLI, Alessandro. Tentando aprender um pouquinho. Algumas reflexões sobre a ética na História Oral. Revista Projeto História, São Paulo, n. 15, p. 13-49, 1997.

SALVARO, Giovana Ilka Jacinto, LAGO, Mara Coelho de Souza e WOLFF, Cristina Scheibe. "Mulheres agricultoras" e "mulheres camponesas": lutas de gênero, identidades políticas e subjetividades. Psicologia \& Sociedade, vol. 25, n. 1, p. 79-89, 2013.

SCOTT, Joan. Gênero: uma categoria útil de análise histórica. Educação e realidade, Porto Alegre: UFRGS, v.20, n.2, p. 5-22, jul./dez. 1995.

SOIHET, Rachel. História das mulheres. In: CARDOSO, Ciro Flamarion: VAINFAS, Ronaldo. (orgs.). Domínios da História: ensaios de teoria e metodologia. Rio de Janeiro: Campus, 2011. WOODWARD, Kathryn. Identidade e diferença: uma introdução teórica e conceitual. In: Silva, Tomaz Tadeu da Silva; Stuart Hall \& Kathryn Woodward. Identidade e diferença: a perspectiva dos Estudos Culturais. Petrópolis. Vozes, 2000.

WOORTMANN, Ellen; WOORTMANN, Klass. O trabalho da terra: a lógica e a simbólica da lavoura camponesa. Brasília: Editora Universidade de Brasília, 1997. 